\title{
Inhibitory effects on the production of inflammatory mediators and reactive oxygen species by Mori folium in lipopolysaccharide-stimulated macrophages and zebrafish
}

\author{
DA HYE KWON ${ }^{1,2}$, JIN WOO JEONG ${ }^{1,2}$, EUN OK CHOI ${ }^{1,2}$, HYE WON LEE $^{3}$, KI WON \\ LEE $^{4}$, KI YOUNG KIM ${ }^{4}$, SUNG GOO KIM ${ }^{4}$, SU HYUN HONG ${ }^{1}$, GI-YOUNG KIM ${ }^{5}$, CHEOL \\ PARK ${ }^{6}$, HYE-JIN HWANG ${ }^{7}$, CHANG-GUE SON ${ }^{8}$ and YUNG HYUN CHOI ${ }^{1,2}$ \\ ${ }^{1}$ Department of Biochemistry, Dongeui University, College of Korean Medicine, 176 \\ Yangjeong-ro, Busanjin-gu, 47227, Busan, Republic of Korea \\ ${ }^{2}$ Anti-Aging Research Center, Dongeui University, 176 Eomgwangno Busanjin-gu, 47340, Busan, Republic of Korea \\ ${ }^{3}$ KM Convergence Research Division, Korea Institute of Oriental Medicine, 1672 \\ Yuseong-daero, Yuseong-gu, 34054, Daejeon, Republic of Korea \\ ${ }^{4}$ Bio-Port Korea INC, Marine Bio-industry Development Center, 27 Hoenggye- \\ ri, Ilgwang-myeon, 46048, Gijang-gun, Republic of Korea \\ ${ }^{5}$ Laboratory of Immunobiology, Department of Marine Life Sciences, Jeju National \\ University, 102 Jejudaehak-ro, 63243, Jeju, Republic of Korea \\ ${ }^{6}$ Department of Molecular Biology, College of Natural Sciences \& Human Ecology, Dongeui \\ University, 176 Eomgwangno Busanjin-gu, 47340, Busan, Republic of Korea \\ ${ }^{7}$ Department of Food and Nutrition, College of Natural Sciences \& Human Ecology, Dongeui \\ University, 176 Eomgwangno Busanjin-gu, 47340, Busan, Republic of Korea \\ ${ }^{8}$ Liver and Immunology Research Center, Daejeon Oriental Hospital of Oriental Medical College of \\ Daejeon University, 176-9 Daeheung-ro, Jung-gu, 34929, Daejeon, Republic of Korea
}

Manuscript received on December 1, 2016; accepted for publication on January 18, 2017

\begin{abstract}
Mori folium, the leaf of Morus alba L. (Moraceae), has been traditionally used for various medicinal purposes from ancient times to the present. In this study, we examined the effects of water extract of Mori folium (WEMF) on the production of inflammatory mediators, such as nitric oxide (NO) and prostaglandin $\mathrm{E}_{2}\left(\mathrm{PGE}_{2}\right)$, and reactive oxygen species (ROS) in lipopolysaccharide (LPS)-stimulated murine RAW 264.7 macrophages. Our data indicated that WEMF significantly suppressed the secretion of $\mathrm{NO}$ and $\mathrm{PGE}_{2}$ in RAW 264.7 macrophages without any significant cytotoxicity. The protective effects were accompanied by a marked reduction in their regulatory gene expression at the transcription level. WEMF attenuated LPSinduced intracellular ROS production in RAW 264.7 macrophages. It inhibited the nuclear translocation of the nuclear factor-kappa B p65 subunit and the activation of mitogen-activated protein kinases in LPStreated RAW 264.7 macrophages. Furthermore, WEMF reduced LPS-induced NO production and ROS accumulation in zebrafish. Although more efforts are needed to fully understand the critical role of WEMF in the inhibition of inflammation, the findings of the present study may provide insights into the approaches for Mori folium as a potential therapeutic agent for inflammatory and antioxidant disorders.
\end{abstract}

Key words: Mori folium, inflammation, ROS, macrophage, zebrafish.

\footnotetext{
Correspondence to: Yung Hyun Choi

E-mail: choiyh@deu.ac.kr

* Contribution to the centenary of the Brazilian Academy of Sciences.
} 


\section{INTRODUCTION}

Inflammation is a primary protective response of the body involving the activation of immune system processes. The inflammatory response is a highly regulated self-limiting process for identifying and destroying invading pathogens and restoring normal tissue structure and function (Conti et al. 2004, Freire and Van Dyke 2013). However, an excessive inflammatory response has been recognized as the main cause of chronic inflammation, such as in cardiovascular disease, rheumatoid arthritis, inflammatory bowel disease, Alzheimer's disease, and even cancer (Amin et al. 1999, Freire and Van Dyke 2013).

When macrophages are over-activated by inflammatory stimulants, including the gramnegative bacterial endotoxin lipopolysaccharides (LPS), the cells induce the production of inflammatory mediators, including nitric oxide (NO) and prostaglandin $\mathrm{E}_{2}\left(\mathrm{PGE}_{2}\right)$, and inflammatory cytokines along with the activation of several signaling pathways, such as nuclear factorkappa B (NF- $\kappa \mathrm{B})$ and mitogen-activated protein kinases (MAPKs) signaling (Kaminska 2005, Lu et al. 2011, Rigoglou and Papavassiliou 2013, Muralidharan and Mandrekar 2013). Excessive production of these inflammatory mediators and cytokines further provoke deleterious consequences in the pathogenesis of many inflammatory diseases (McDaniel et al. 1996, Muralidharan and Mandrekar 2013).

Another important component of inflammation is oxidative stress, which reflects the imbalance between the production of reactive oxygen species (ROS) and the ability of the biological system to remove them (Brüne et al. 2013, Mills and O'Neill 2016). The overproduced ROS by activated macrophages acts as an important contributor to the manifestation of inflammation (Varga et al. 2013, Mills and O'Neill 2016), and it is also involved in the production of inflammatory mediators in LPS- stimulated macrophages (Haddad and Land 2002). Consequently, the suppression of the production of inflammatory factors by blocking macrophage activation emerges as a potential therapeutic approach to relieve the progression of inflammatory and oxidative disorders (Cunha et al. 2008, Zhang and Wang 2014). For this reason, the development of anti-inflammatory and/or antioxidant agents, which can control the activation of macrophages, is necessary for the prevention and treatment of various diseases.

Recent data have convincingly pointed out that natural resources have been widely and safely consumed over centuries and that most of them have a wide range of diverse biological activities with few side effects (Bocanegra et al. 2009, Abuajah et al. 2015). Among these natural resources, Morus alba L. that belongs to the Moraceae family, is one of the most valuable and rich in natural ingredients plant. This tree is widely distributed in Eastern Asia countries including Korea, China and Japan but now is cultivated throughout worldwide. The leaf of plant, Mori folium (Supplementary Material, Figure S1), has been used in traditional medicine for the treatment of various diseases (Yang et al. 2014, Chan et al. 2016). Mori folium exhibits a variety of pharmacological activities, such as anti-microbial (Tirupathi et al. 2011), antitumor (Deepa et al. 2013), anti-obesity (Sugimoto et al. 2009, Ann et al. 2015), anti-hypotensive (Kobayashi et al. 2010), neuroprotective (Xiang et al. 2010), anti-diabetic (Naowaboot et al. 2009), and immunomodulatory potentials (Kwon et al. 2016). In addition, Mori folium possesses free radical-scavenging activities (Kim and Jang 2011, Iqbal et al. 2012, Raman et al. 2016), which may explain its antioxidant ability (Khan et al. 2013, Kim et al. 2014, Raman et al. 2016). Previous studies, including our recent data, indicated that the extracts and components of Mori folium have strong anti-inflammatory properties (Hong et al. 2002, Shibata et al. 2007, Chao et al. 2009, Jeong 
et al. 2016). Despite these encouraging studies, the effects and molecular mechanisms responsible for the anti-inflammatory and antioxidant potentials of Mori folium have remained elusive. Therefore, we investigated in this study the anti-inflammatory and antioxidant actions of the water extract of Mori folium (WEMF) in LPS-stimulated RAW 264.7 macrophage cells by measuring its ability to inhibit $\mathrm{NO}, \mathrm{PGE}_{2}$, and ROS production. Moreover, we confirmed the protective effects of WEMF on NO and ROS generation in zebrafish larvae.

\section{MATERIALS AND METHODS}

\section{PREPARATION AND FINGERPRINTING OF WEMF}

The dried leaves of M. alba were obtained from Bio-Port Korea, Inc. (Busan, Republic of Korea), and WEMF was prepared as previous described (Jeong et al. 2016). WEMF was dissolved in a $100 \mathrm{mg} / \mathrm{ml}$ concentration with distilled water, and the stock solution was then diluted with culture medium to the desired concentration prior to use. To confirmation the reproducibility of WEMF, we conducted fingerprinting using a highperformance liquid chromatography (HPLC)-based compositional analysis with two main reference compounds, namely, rutin hydrate and astragalin. All analyses were performed using an Agilent 1100 series HPLC instrument (Agilent Technologies, San Jose, CA, USA) as previously reported (Lee et al. 2014). The representative sample chromatogram and quantitative analysis are illustrated in Figure 1.

\section{CELL CULTURE AND CELL VIABILITY ASSAY}

The RAW 264.7 murine macrophage cell line was obtained from the Korean Cell Line Bank (Seoul, Republic of Korea) and cultured at $37^{\circ} \mathrm{C}$ in $5 \% \mathrm{CO}_{2}$ containing Dulbecco $\square \mathrm{s}$ modified Eagle's medium (WelGENE Inc., Daegu, Republic of Korea) supplemented with $10 \%$ fetal bovine serum (WelGENE Inc.), $100 \mathrm{U} / \mathrm{ml}$ of penicillin, and $100 \mathrm{mg} / \mathrm{ml}$ of streptomycin (Sigma-
Aldrich Chemical Co., St. Louis, MO, USA). A colorimetric 3-[4,5-dimethylthiazol-2-yl]-2,5diphenyltetrazolium bromide (MTT, SigmaAldrich Chemical Co.) assay was performed to measure cell viability. In brief, RAW 264.7 cells were treated with various concentrations of WEMF for $24 \mathrm{~h}$ or pretreated with WEMF for 1 $\mathrm{h}$ before stimulation with $500 \mathrm{ng} / \mathrm{ml}$ LPS (SigmaAldrich Chemical Co.) for $24 \mathrm{~h}$. After incubation, the medium was discarded, and MTT solution (5 $\mathrm{mg} / \mathrm{mL}$ in phosphate-buffered saline, PBS) was added to each well and incubated for another $3 \mathrm{~h}$ at $37^{\circ} \mathrm{C}$. The medium was removed and dimethyl sulfoxide (Sigma-Aldrich Chemical Co.) was added to dissolve the formazan dye. The optical density was then read at $560 \mathrm{~nm}$ using a microplate spectrophotometer (Molecular Devices, Sunnyvale, CA, USA) to determine cell viability (Oh et al. 2015).

MEASUREMENT OF NO PRODUCTION IN RAW 264.7 MACROPHAGES

The production of NO in culture supernatants was assayed using Griess reagent (Sigma-Aldrich Chemical Co.). For this assay, the supernatant was collected and mixed with the same volume of Griess reagent for $10 \mathrm{~min}$ at room temperature in the dark. Absorbance was measured at $540 \mathrm{~nm}$ on a microplate reader, and NO concentrations were calculated by referencing a standard curve generated by known concentrations of sodium nitrite (Lee et al. 2015a).

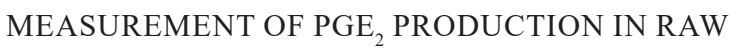
264.7 MACROPHAGES

To measure the production of $\mathrm{PGE}_{2}$, the cells were cultured under the same conditions as those for the NO measurement assay. The levels of $\mathrm{PGE}_{2}$ concentrations in cultured media were determined by an enzyme-linked immunosorbent assay (ELISA) kit (R\&D Systems, Minneapolis, MN, 
a)

b)
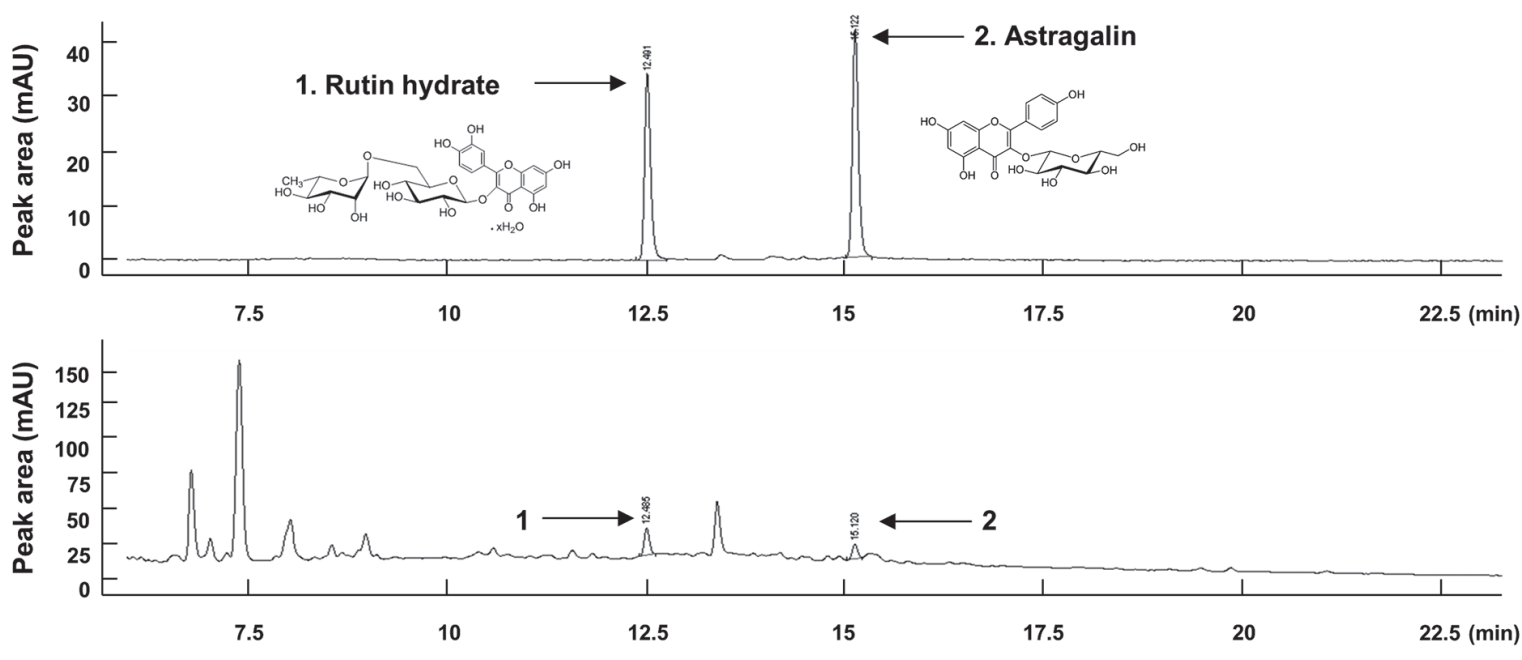

c)

\begin{tabular}{cccc}
\hline Ref No. & Retention time $(\mathrm{min})$ & Compound & Mean \pm SD $(\mathrm{ug} / \mathrm{mg})$ \\
\hline 1 & 12.50 & Rutin hydrate & $0.412 \pm 0.010$ \\
\hline 2 & 15.15 & Astragalin & $0.147 \pm 0.017$
\end{tabular}

Figure 1 - Fingerprint analysis of WEMF using HPLC. The two reference components (a) and WEMF (b) were analyzed by HPLC analysis. The quantitative data of WEMF (c) for rutin hydrate and astragalin were presented.

USA), according to the manufacturer's instructions (Wang et al. 2015).

RNA ISOLATION AND REVERSER TRANSCRIPTION POLYMERASE CHAIN REACTION (RT-PCR)

Total RNA was isolated from cells using TRIzol reagent (Invitrogen Life Technologies, Carlsbad, CA, USA) according to the manufacturer's instructions and reverse transcribed using the M-MLV reverse transcriptase kit (BioNEER, Daejeon, Republic of Korea) to produce cDNAs. RT-generated cDNAs encoding iNOS and COX2 genes were amplified by PCR using the desired primers (BioNEER). Following amplification, the PCR products were separated by $1.5 \%$ agarose gel electrophoresis, stained with ethidium bromide, and visualized by ultraviolet illumination. In a parallel experiment, glyceraldehyde 3-phosphate dehydrogenase was used as an internal control.

\section{PROTEIN EXTRACTION AND WESTERN BLOT} ANALYSIS

The cells were collected and resuspended in an extraction lysis buffer [25 mM Tris-Cl (pH 7.5), $250 \mathrm{mM} \mathrm{NaCl}, 5 \mathrm{mM}$ ethylene diaminetetra acetic acid, 1\% NP-40, $1 \mathrm{mM}$ pheny-methylsulfonyl fluoride, and $5 \mathrm{mM}$ dithiothreitol] for $30 \mathrm{~min}$ at $4^{\circ} \mathrm{C}$. In a parallel experiment, nuclear and cytosolic proteins were separated using NE-PER nuclear and cytosolic extraction reagents (Pierce Biotechnology, Rockford, IL, USA) according to the manufacturer's protocol. Equal amounts of protein from each sample were separated by sodium dodecyl sulfate (SDS)-polyacrylamide gel electrophoresis at 90 $\mathrm{V}$ for $2 \mathrm{~h}$ and transferred onto polyvinylidene fluoride membranes (Millipore, Bedford, MA, USA). Thereafter, the membranes were incubated overnight at $4^{\circ} \mathrm{C}$ with the corresponding primary antibodies purchased from Santa Cruz Biotechnology, Inc. (Santa Cruz, CA, USA) and 
Cell Signaling Technology, Inc. (Boston, MA, USA). Then, the membranes were incubated with the appropriate secondary antibodies conjugated to horseradish peroxidase (Amersham Co., Arlington Heights, IL, USA)) at room temperature for $2 \mathrm{~h}$. Using an enhanced chemiluminescence (ECL, Amersham Co.) detection system, immunoreactive bands were detected.

IMMUNOFLUORESCENT STAINING FOR NF-KB P65 IN RAW 264.7 MACROPHAGES

The NF- $\kappa$ B p65 nuclear translocalization was detected by an immunofluorescence assay using a fluorescence microscope. For this study, RAW 246.7 cells were pretreated with WEMF for $1 \mathrm{~h}$ and then stimulated with LPS for $1 \mathrm{~h}$. The cells were fixed with $3.7 \%$ paraformaldehyde (SigmaAldrich Chemical Co.) in PBS for $10 \mathrm{~min}$ at $4^{\circ} \mathrm{C}$, permeabilized with $0.4 \%$ Triton X-100 in PBS for $10 \mathrm{~min}$, and blocked with $5 \%$ bovine serum albumin for $1 \mathrm{~h}$. The cells were probed with anti-p65 NF$\kappa \mathrm{B}$ antibody (Santa Cruz Biotechnology, Inc.) overnight at $4{ }^{\circ} \mathrm{C}$ and then incubated with fluorescein isothiocyanate-conjugated donkey anti-rabbit IgG (Jackson ImmunoResearch Laboratories Inc., West Grove, PA, USA) for $2 \mathrm{~h}$ at room temperature. The position of the cell nucleus was determined with 4,6-diamidino-2-phenylindole (DAPI, SigmaAldrich Chemical Co.) solution $(1 \mathrm{mg} / \mathrm{ml})$ for 15 min. After washing the cells with PBS, fluorescence was visualized using a fluorescence microscope (Carl Zeiss, Oberkochen, Germany).

\section{MEASUREMENT OF ROS GENERATION IN RAW 264.7 MACROPHAGES}

To measure the ROS levels, the cells were washed twice with PBS and lysed with $1 \%$ Triton X-100 in PBS for $10 \mathrm{~min}$ at $37^{\circ} \mathrm{C}$. The cells were then stained with $10 \mu \mathrm{M} 2^{\prime}, 7^{\prime}$-dichlorofluorescein diacetate (DCF-DA, Molecular Probes, Eugene, OR, USA) for $20 \mathrm{~min}$ at room temperature in the dark. The green fluorescence emitted by DCF was recorded at $515 \mathrm{~nm}$ using a flow cytometer (Becton Dickinson, San Jose, CA, USA), and 10,000 events were counted per sample (Eom et al. 2015). Image analysis for the generation of intracellular ROS was acquired using a fluorescence microscope.

\section{ZEBRAFISH EMBRYO AND LARVAE MAINTENANCE}

Adult zebrafish were obtained from Dr. Hyo-Jong Lee, College of Pharmacy, Inje University (Gimhae, Republic of Korea) and maintained at $28.5^{\circ} \mathrm{C}$ with a $14: 10 \mathrm{~h}$ light/dark cycle in a recirculating tank system using local tap water ( $\mathrm{pH} 7.2 \square 7.6$, salinity $0.03 \% \square 0.04 \%$ ). The embryos were obtained from natural spawning within $30 \mathrm{~min}$ and maintained at a density of about 50 embryos per $100 \mathrm{~mm}^{2}$ in a Petri dish containing media, as previously reported (Wijesinghe et al. 2014). The entire study design and experimental procedures were approved by the Dongeui University Animal Care and Use Committee (Busan, Republic of Korea).

\section{MEASUREMENT OF NO AND ROS PRODUCTION IN ZEBRAFISH LARVAE}

Approximately three days post-fertilization (dpf), embryos $(n=25)$ were transferred to individual wells of a 24-well plate and maintained in embryo media containing sterile distilled water (vehicle control), $800 \mu \mathrm{g} / \mathrm{ml}$ WEMF (final concentration), $10 \mu \mathrm{g} / \mathrm{ml}$ LPS (final concentration), or $800 \mu \mathrm{g} / \mathrm{ml}$ WEMF for $1 \mathrm{~h}$ followed by treatment with $10 \mu \mathrm{g} / \mathrm{ml}$ LPS, except the larvae in the control group, for up to 4 dpf. The generation of NO and ROS in zebrafish larvae was analyzed using fluorescent probe dyes, 4-amino-5-methylamino-2'7' difluorofluorescein diacetate (DAF-FM-DA, Molecular Probes) and DCF-DA, respectively. After $4 \mathrm{dpf}$, the larvae were transferred into 24-well plates and incubated with DAF-FM DA $(5 \mu \mathrm{M})$ and DCF-DA $(20 \mu \mathrm{g} /$ $\mathrm{ml}$ ) solution for $1 \mathrm{~h}$ in the dark at $28.5^{\circ} \mathrm{C}$, and then anaesthetized using 1-phenoxy-2-propanol (1/500 dilution, Acros Organics, Morris Plains, NJ, 
USA). The images of stained larvae were observed for NO and ROS generation under a fluorescence microscope, and fluorescence intensity of individual larvae was quantified at an excitation wavelength of $485 \mathrm{~nm}$ and an emission wavelength of 535 $\mathrm{nm}$ using a spectrophotometer and Image J 1.46r software (Wayne Rasband, National Institutes of Health, Bethesda, MD, USA), respectively. The generation of NO and ROS was calculated by comparing the fluorescence intensity of treatment larvae with that of the controls (Wijesinghe et al. 2014).

\section{STATISTICAL ANALYSIS}

All data are presented as mean \pm standard deviation (SD). Significant differences among groups were determined using the unpaired Student's t-test. A value of $p<0.05$ was accepted as an indication of statistical significance. All the figures shown here reflect the data obtained from at least three independent experiments.

\section{RESULTS}

CYTOTOXIC EFFECTS OF WEMF AND LPS ON RAW 264.7 MACROPHAGES

To exclude the cellular toxicity caused by WEMF treatment, RAW 264.7 cells were treated with WEMF and/or LPS for $24 \mathrm{~h}$. The MTT assay showed that WEMF of up to $1,000 \mu \mathrm{g} / \mathrm{ml}$ in the presence or absence of $100 \mathrm{ng} / \mathrm{ml}$ LPS was not cytotoxic (Figure 2). Therefore, we selected 800 $\mu \mathrm{g} / \mathrm{ml}$ WEMF as the maximum concentration for further experiments in RAW 264.7 cells.

WEMF SUPPRESSED LPS-INDUCED NO AND PGE ${ }_{2}$ PRODUCTION IN RAW 264.7 MACROPHAGES

To determine the inhibitory properties of WEMF on LPS-induced $\mathrm{NO}$ and $\mathrm{PGE}_{2}$ production in RAW 264.7 cells, the cells were pretreated with the indicated concentrations of WEMF for $1 \mathrm{~h}$ and then stimulated with $100 \mathrm{ng} / \mathrm{ml}$ LPS for another

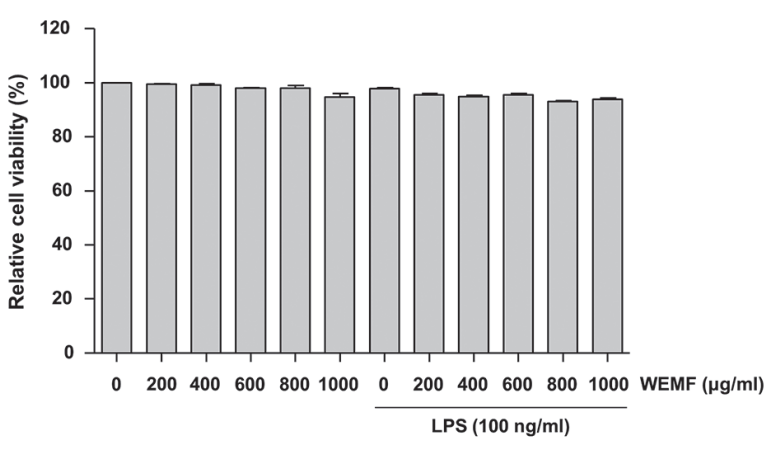

Figure 2 - Effects of WEMF on the cell viability of RAW 264.7 macrophages. The cells were treated with various concentrations of WEMF for $24 \mathrm{~h}$ or pretreated with the indicated concentrations of WEMF for $1 \mathrm{~h}$ prior to LPS (100 $\mathrm{ng} / \mathrm{ml}$ ) treatment for $24 \mathrm{~h}$. Cell viability was assessed with an MTT reduction assay, and the results were expressed as the percentage of surviving cells over control cells (no addition of WEMF and LPS). Values represent the means \pm SD of three independent experiments.

$24 \mathrm{~h}$. The levels of $\mathrm{NO}$ and $\mathrm{PGE}_{2}$ in the culture supernatants were determined by Griess reaction assay and ELISA, respectively. As indicated in Figure $3 \mathrm{a}$ and $\mathrm{b}$, stimulation with LPS markedly induced the production of $\mathrm{NO}$ and $\mathrm{PGE}_{2}$ compared with not stimulating with LPS. However, WEMF significantly inhibited $\mathrm{NO}$ and $\mathrm{PGE}_{2}$ secretion in RAW 264.7 cells in a concentration-dependent manner.

\section{WEMF ATTENUATES LPS-INDUCED INOS AND COX-2 EXPRESSION IN RAW 264.7 MACROPHAGES}

We next investigated if the inhibitory effects of WEMF on $\mathrm{NO}$ and $\mathrm{PGE}_{2}$ production were related to the regulation of the expression of their synthesis enzymes, iNOS and COX-2, respectively. As shown in Figure 3c and d, WEMF concentrationdependently inhibited the protein and mRNA expression of iNOS and COX-2 in the LPSstimulated RAW 264.7 cells. These data indicate that WEMF suppresses $\mathrm{NO}$ and $\mathrm{PGE}_{2}$ production by reducing the expression of their encoding genes. 
a)

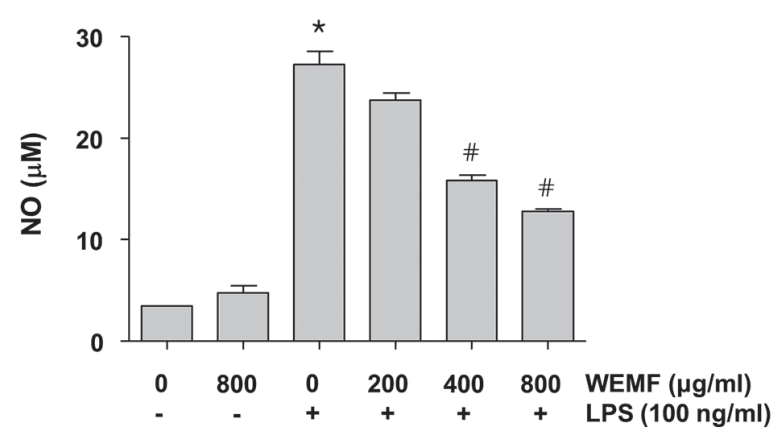

c)

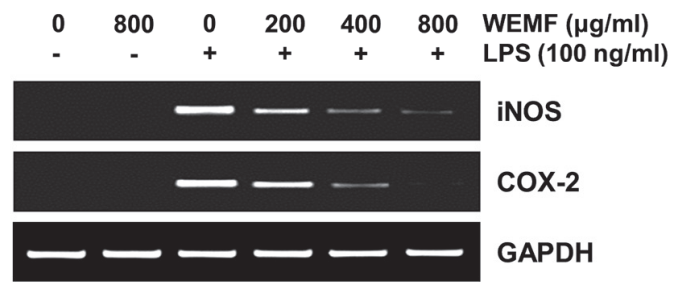

b)

d)
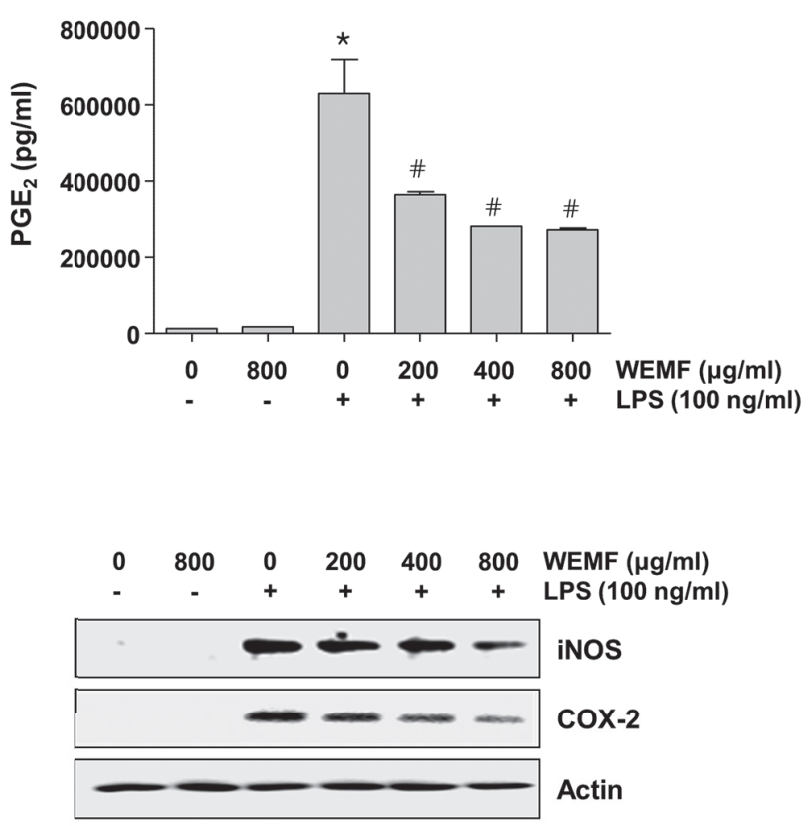

Figure 3 - Inhibition of NO and PGE ${ }_{2}$ production by WEMF in LPS-stimulated RAW 264.7 macrophages. The cells were pretreated with the indicated concentrations of WEMF for $1 \mathrm{~h}$ prior to incubation with $100 \mathrm{ng} / \mathrm{ml} \mathrm{LPS} \mathrm{for} 24 \mathrm{~h}$. The levels of NO (a) and PGE 2 (b) in culture media were measured by Griess assay and a commercial ELISA kit, respectively. Each value indicates the mean \pm $\mathrm{SD}$ and is representative of the results obtained from three independent experiments $\left({ }^{\#} \mathrm{p}<0.05\right.$ compared with the control; $* \mathrm{p}<0.05$ compared with cells cultured with $100 \mathrm{ng} / \mathrm{ml}$ LPS). (c) The total RNAs were isolated from cells grown under the same conditions as those in Figure 3 and prepared for the RT-PCR analysis of the iNOS and COX-2 mRNA expression using the indicated primers. (d) Cell lysates were prepared for Western blot analysis, with antibodies specific for murine iNOS and COX-2, and for an ECL detection system. The experiment was repeated three times and similar results were obtained. GAPDH and actin were used as the internal controls for the RT-PCR and Western blot analysis, respectively.

WEMF BLOCKS LPS-INDUCED NF-KB NUCLEAAR TRANSLOCATION IN RAW 264.7 MACROPHAGES

As active NF- $\kappa \mathrm{B}$ translocates to the nucleus where it activates its target genes including, iNOS, COX2 , and pro-inflammatory cytokines, by binding to their promoter regions (Lu et al. 2011, Rigoglou and Papavassiliou 2013), we investigated whether or not WEMF attenuates the LPS-induced nuclear translocation of NF- $\kappa \mathrm{B}$ in RAW 264.7 cells. The immunoblotting data using cytoplasmic and nuclear extracts indicated that WEMF pretreatment inhibited the NF- $\mathrm{B}$ p65 subunit nuclear accumulation, which was associated with the attenuation of I $\kappa \mathrm{B} \alpha$ degradation in LPS-stimulated RAW 264.7 cells (Figure 4a). Consistent with these results, immunocytochemistry analysis also indicated that NF- $\kappa \mathrm{B}$ p65 was normally sequestered in the cytoplasm following stimulation with LPS. However, the LPS-mediated nuclear translocation of NF- $\kappa \mathrm{B}$ was considerably blocked by pretreatment with WEMF (Figure $4 b$ ). These results indicated that WEMF attenuated the transcriptional activation of NF- $\kappa \mathrm{B}$, which controls the expression of pro-inflammatory genes in LPStreated RAW 264.7 cells.

\section{WEMF REDUCES THE ACTIVATION OF MAPKS IN LPS-STIMULATED RAW 264.7 MACROPHAGES}

As the activation of MAPKs is crucial for LPSstimulated $\mathrm{NF}-\kappa \mathrm{B}$ activation and the subsequent transcriptional activation of inflammatory gene 
a)

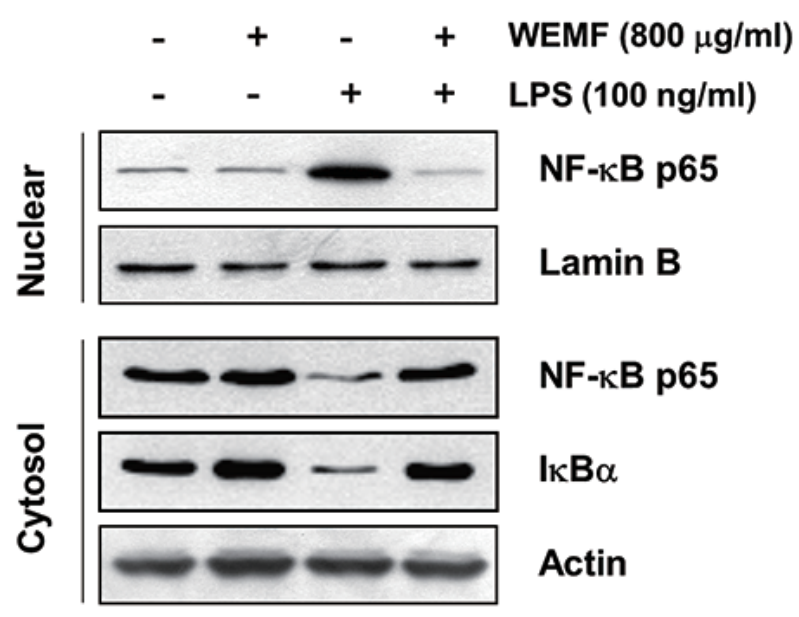

b)

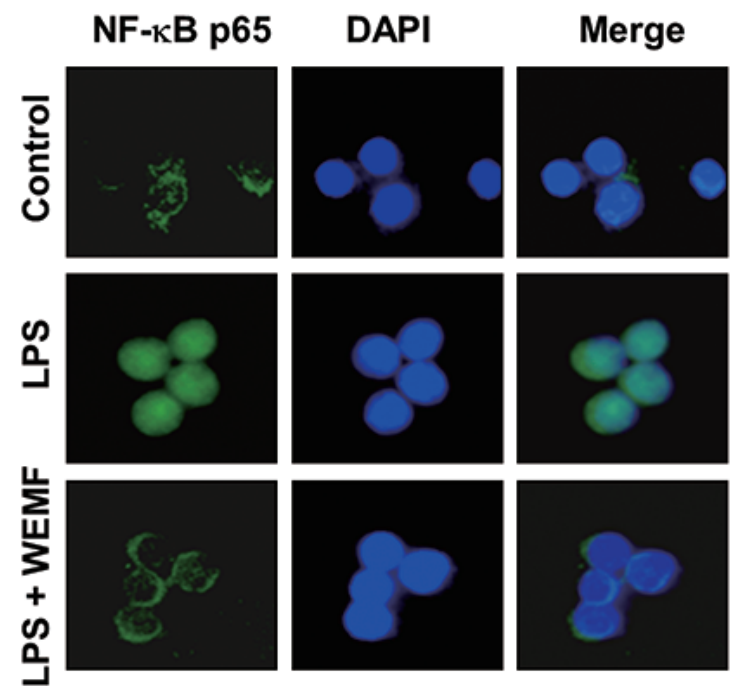

Figure 4 - Inhibition of NF- $\mathrm{B}$ n nuclear translocation by WEMF in LPS-stimulated RAW 264.7 macrophages. (a) The cells were pretreated with $800 \mu \mathrm{g} / \mathrm{ml}$ WEMF for $1 \mathrm{~h}$ before $100 \mathrm{ng} / \mathrm{ml}$ LPS treatment for $1 \mathrm{~h}$. The nuclear and cytosolic proteins were prepared

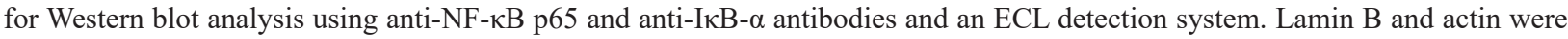
used as internal controls for the nuclear and cytosolic fractions, respectively. (b) The cells were pretreated with $800 \mu \mathrm{g} / \mathrm{ml} \mathrm{WEMF}$ for $1 \mathrm{~h}$ before $100 \mathrm{ng} / \mathrm{ml}$ LPS treatment. After $1 \mathrm{~h}$ of incubation, the localization of NF- $\mathrm{KB}$ p 65 was visualized with fluorescence microscopy after immunofluorescence staining with anti-NF- $\kappa$ B p65 antibody (green). The cells were also stained with DAPI to visualize the nuclei (blue). The results are representative of those obtained from three independent experiments.

expression (Kaminska 2005, Muralidharan and Mandrekar 2013), we analyzed the phosphorylation of MAPKs, such as extracellular signal-regulated kinase (ERK), c-Jun N-terminal kinase (JNK), and p38 MAPK, by Western blot analysis. As shown in Figure 5, stimulation with LPS resulted in the marked phosphorylation of ERK, JNK, and p38 MAPK, and their total expressions did not have any significant change. However, WEMF concentration-dependently blocked the LPSinduced phosphorylation of three MAPKs. The result showed that WEMF suppressed MAPKs signaling pathway to reduce inflammatory responses in LPS-induced RAW 264.7 cells.

\section{WEMF SUPPRESSES LPS-INDUCED \\ ACCUMULATION OF ROS IN RAW 264.7 \\ MACROPHAGES}

As oxidative stress is partly involved in the initiation of inflammation (Brüne et al. 2013, Mills and O'Neill 2016), we examined whether or not WEMF could reduce the LPS-induced generation of ROS in RAW 264.7 cells using DCF-DA staining. The results of the flow cytometric assay indicated that the accumulation of intracellular ROS was observed at $0.5 \mathrm{~h}$, and that the levels continued to increase up to $2 \mathrm{~h}$ by LPS treatment (Figure 6a). However, the increase in LPS-stimulated ROS production was markedly attenuated by pretreatment with WEMF (Figure $6 \mathrm{~b}$ and $\mathrm{c}$ ). As a positive control, the ROS scavenger N-acetyl-1-cysteine (NAC) also effectively attenuated LPS-induced ROS generation, but WEMF itself did not contribute to the ROS generation. This finding suggests that the anti-inflammatory potential of WEMF may be associated with its antioxidant effects on RAW 264.7 cells.

\section{WEMF DOWNREGULATES LPS-INDUCED NO AND ROS PRODUCTION IN ZEBRAFISH}

To confirm the in vivo protective effects of WEMF on LPS-induced NO generation, we visualized 


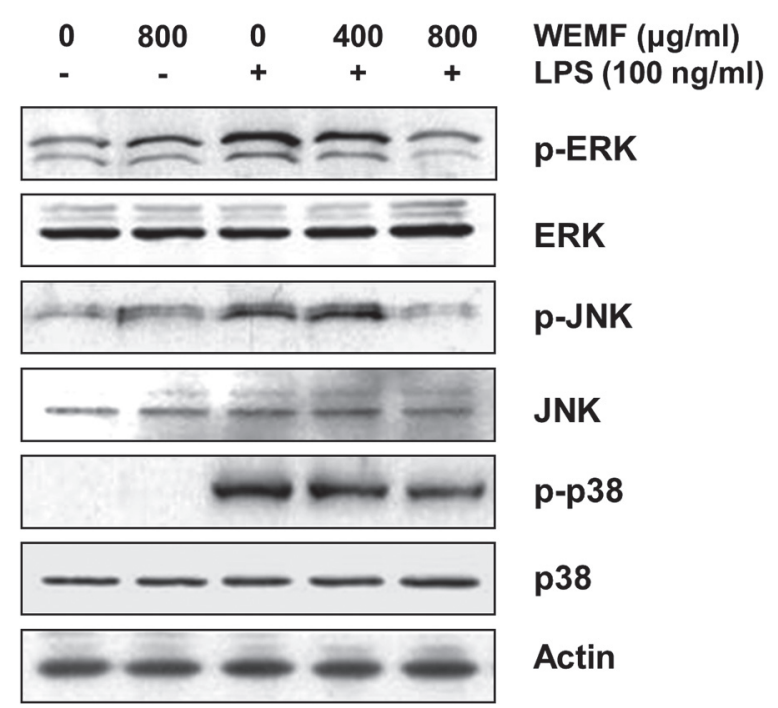

Figure 5 - Effects of WEMF on the LPS-induced phosphorylation of MAPKs in RAW 264.7 macrophages. The cells were treated with the indicated concentrations of WEMF for $1 \mathrm{~h}$ prior to treatment with $100 \mathrm{ng} / \mathrm{ml} \mathrm{LPS} \mathrm{for} 30 \mathrm{~min}$. Total proteins were isolated and subjected to SDS-polyacrylamide gels, followed by Western blot analysis using the indicated antibodies. Proteins were visualized using the ECL detection system.

DAF-FM-DA staining in a zebrafish model. As shown in Figure 7a and b, the control, which was not treated with LPS or WEMF, and WEMF alone groups generated a clear image, thus indicating that WEMF alone did not affect the basal NO levels. However, stimulation of the zebrafish larvae with LPS markedly generated fluorescence image, thus suggesting that NO generation took place in the presence of LPS and WEMF reduced the LPSstimulated elevation of NO production. We also evaluated the inhibitory effect of WEMF on LPSinduced ROS accumulation. Microphotographs of DCF-DA staining revealed excessive ROS accumulation after LPS stimulation. By contrast, when the zebrafish larvae were treated with WEMF prior to LPS administration, an effective reduction in the generation of ROS was observed (Figure 7c and d), thus suggesting that WEMF also inhibited LPS-stimulated ROS production in vivo.

\section{DISCUSSION}

Inflammation is a host defense mechanism against pathogenic challenges, and multiple events are involved in the development of inflammation. During infection by gram-negative bacterial LPS, membrane-bound pattern recognition receptor Tolllike receptor 4 (TLR4) is a critical driver of immune responses (Aderem and Ulevitch 2000, Nikaido 2003). The activation of TLR4 pathway leads to intracellular signaling pathways that culminate in the activation of several intracellular signaling pathways, including NF- $\kappa \mathrm{B}$ and MAPKs. The consequent activation of macrophages promotes inflammation through the aberrant production of pro-inflammatory mediators and cytokines that recruit additional immune cells to sites of infection or tissue injury (Aderem and Ulevitch 2000, Nikaido 2003). Regarding the importance of pro-inflammatory cytokines in inflammatory responses, the pro-inflammatory mediators of NO and $\mathrm{PGE}_{2}$ play crucial roles in the development of chronic inflammatory disease (Rocca and FitzGerald 2002, Kim et al. 2005). In addition, LPS exerts its inflammatory effects by inducing the expression of iNOS and COX-2, which directly stimulates the high production of $\mathrm{NO}$ and $\mathrm{PGE}_{2}$, respectively. Therefore, a compound capable of preventing the release of pro-inflammatory mediators or downregulating iNOS or COX-2 expression by the inactivation of macrophages may possess anti-inflammatory activities. In this study, we observed that WEMF significantly attenuated the LPS-induced increase in $\mathrm{NO}$ and $\mathrm{PGE}_{2}$, which are representative pro-inflammatory mediators, in RAW 264.7 macrophages by down-regulating iNOS and COX-2 expression at both the protein and mRNA levels without cytotoxicity. These indicated the inhibitory effect of WEMF on NO and $\mathrm{PGE}_{2}$ production was mainly due to the inhibitions of iNOS and COX-2 mRNA and protein expressions. Thus, the results support WEMF being a promising 
a)

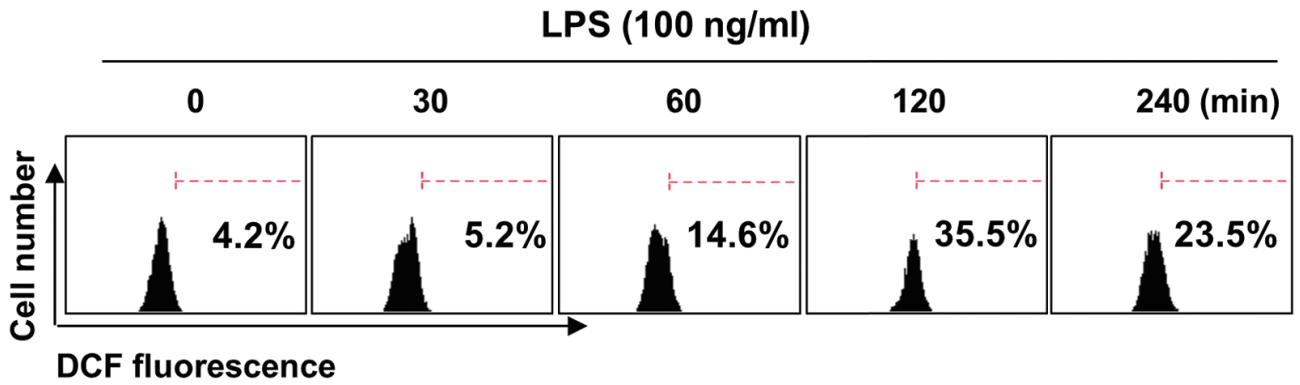

b)

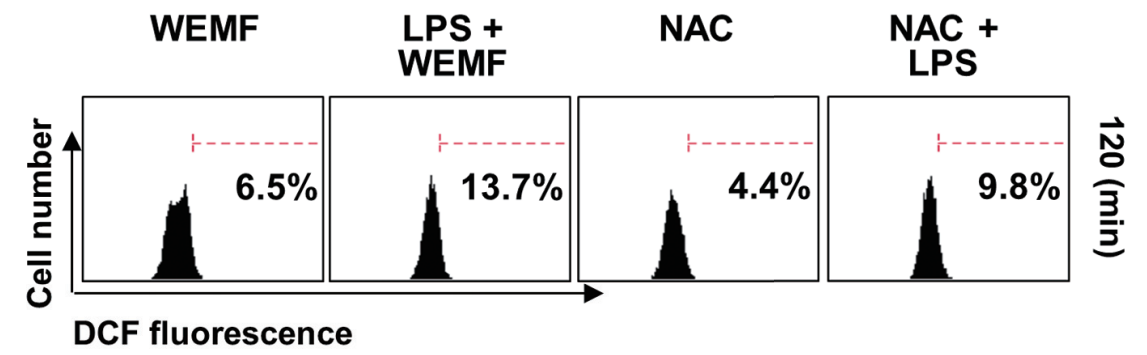

c)
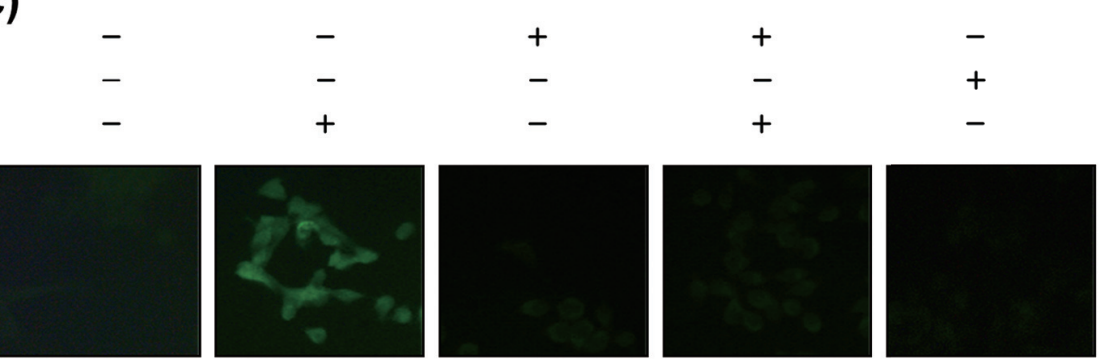
- WEMF $(800 \mu \mathrm{g} / \mathrm{ml})$
+ NAC $(10 \mathrm{mM})$
$+\quad$ LPS $(100 \mathrm{ng} / \mathrm{ml})$

Figure 6 - Effects of WEMF on LPS-induced ROS production in RAW 264.7 macrophages. The cells were treated with 100 ng/ $\mathrm{ml}$ LPS for the indicated time (a) or pre-incubated with or without $800 \mu \mathrm{g} / \mathrm{ml} \mathrm{WEMF}$ or $10 \mathrm{mM} \mathrm{NAC}$ for $1 \mathrm{~h}$ and then stimulated with $100 \mathrm{ng} / \mathrm{ml} \mathrm{LPS} \mathrm{for} 2 \mathrm{~h}$ (b and c). The cells were incubated with $10 \mu \mathrm{M}$ DCF-DA for $30 \mathrm{~min}$ at $37^{\circ} \mathrm{C}$. The cells were collected and DCF fluorescence was measured by a flow cytometry. Values represent the means \pm SD of two independent experiments. (c) Images were obtained using a fluorescence microscope, presented from one experiment, and were representative of at least three independent experiments.

target for inhibiting the early steps in inflammatory pathways.

$\mathrm{NF}-\kappa \mathrm{B}$ has been shown to play an important role in various inflammatory states as a key transcription factor for many inflammation-associated enzymes and cytokine genes, which contain NF- $\kappa \mathrm{B}$ binding motifs within their respective promoters ( $\mathrm{Lu}$ et al. 2011, Rigoglou and Papavassiliou 2013). NF- $\kappa$ B, a dimer of p65 and p50 subunits, is normally retained in the cytoplasm because of its association with its endogenous inhibitor, I $\mathrm{K} B-\alpha$. Once activated by inflammatory stimulants, including LPS, IкB- $\alpha$ is rapidly phosphorylated and degraded through a proteasome-mediated pathway, followed by a nuclear translocation of $\mathrm{NF}-\kappa \mathrm{B}$, thus resulting in the transcriptional induction of inflammationassociated genes (Nikaido 2003, Rigoglou and Papavassiliou 2013). MAPKs, a family of serine/ threonine protein kinases including ERK, JNK, and p38 MAPK, are also directly involved in controlling signaling events that contribute to the production of pro-inflammatory factors in activated macrophages through the activation of NF- $\kappa$ B (Kaminska 2005, Muralidharan and Mandrekar 2013). Therefore, pharmacologic agents that effectively modulate $\mathrm{NF}-\kappa \mathrm{B}$ and MAPKs activation are promising 
a)

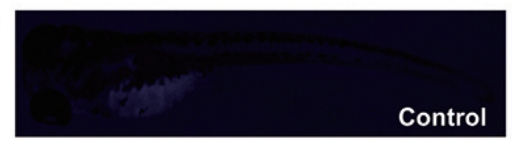

WEMF $(800 \mu \mathrm{g} / \mathrm{ml})$

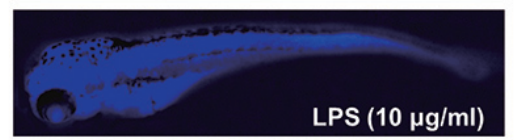

WEMF + LPS

c)

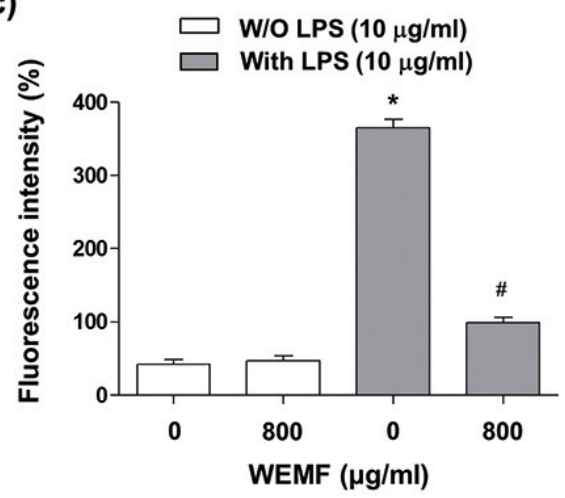

b)

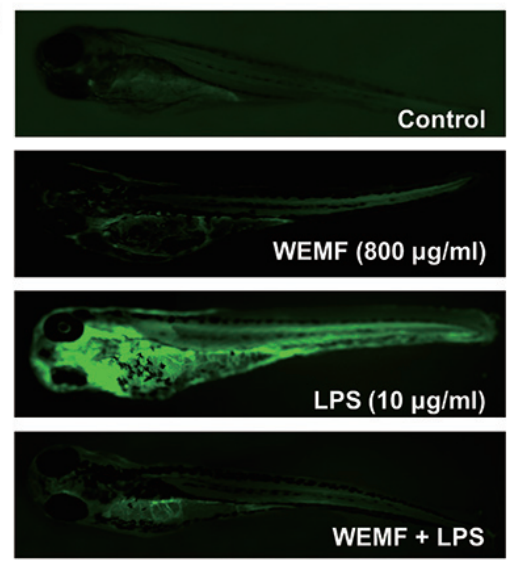

d)

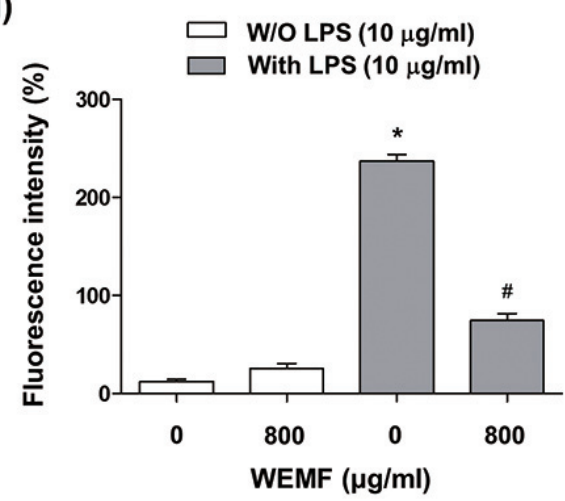

Figure 7 - Protective effect of WEMF on LPS-induced NO and ROS generation in zebrafish larvae. The zebrafish larvae were treated with $800 \mu \mathrm{g} / \mathrm{ml} \mathrm{WEMF} \mathrm{and} 10 \mu \mathrm{g} / \mathrm{ml}$ LPS for $24 \mathrm{~h}$ or pretreated with $800 \mu \mathrm{g} / \mathrm{ml} \mathrm{WEMF} \mathrm{for} 1 \mathrm{~h}$ prior to incubation with $10 \mu \mathrm{g} / \mathrm{ml}$ LPS for $24 \mathrm{~h}$ ( $\mathrm{a}$ and $\mathrm{b}$ ). The levels of NO and ROS generation were observed under a fluorescence microscope after staining with DAF-FM-DA and DCF-DA, respectively ( $c$ and d). The fluorescence intensities of NO and ROS levels in individual zebrafish larvae were quantified. The values represented the means $\pm \mathrm{SD}$ of three independent experiments $\left({ }^{\#} \mathrm{p}<0.05\right.$ compared with the control; $* \mathrm{p}<0.05$ compared with the LPS-treated group).

candidates for treating various inflammatory diseases. To investigate the molecular mechanism of WEMF-mediated inhibition of inflammatory substances, its effect on the activation of MAPKs and NF- $\mathrm{kB}$ was evaluated. In the present study, we found that WEMF strongly suppressed the translocation of activated NF- $\kappa \mathrm{B}$ to the nucleus and degradation of I $\mathrm{KB}-\alpha$ was also inhibited. These findings indicate that WEMF inhibits $N F-\kappa B$ activation by suppressing $\mathrm{I} \kappa \mathrm{B}-\alpha$ degradation and translocation of NF- $\kappa \mathrm{B}$ from the cytosol into the nucleus in LPS-induced RAW 264.7 macrophages. The current study also demonstrated that WEMF concentration-dependently diminished the phosphorylation of ERK, JNK, and p38 MAPK by LPS treatment. These data suggest that suppression of MAPKs phosphorylation by WEMF might also be involved in the inhibition of the LPS-induced production of proinflammatory substances by RAW 264.7 macrophages. Taken together, our results indicate that WEMF suppresses inflammatory mediators, $\mathrm{NO}$ and $\mathrm{PGE}_{2}$ by inhibiting NF- $\kappa \mathrm{B} \mathrm{B}$ and MAPKs signaling pathways.

Oxidative stress, which represents the overproduction of ROS, is strongly associated with other pathological statuses, including inflammation 
(Brüne et al. 2013, Mills and O'Neill, 2016). Moreover, during chronic inflammation, ROS amplifies inflammatory signals in macrophages through the activation of NF- $\mathrm{BB}$ signaling pathway and the over-expression of inflammation-associated genes (Kauppinen et al. 2013, Tan et al. 2016). Furthermore, MAPKs are also redox sensitive, and ROS targets the cysteines within the proteins and alters the kinase activation, which further activates redox-sensitive MAPKs (Rahman and MacNee 1998, Fu et al. 2009). Thus, we investigated the inhibitory effect of WEMF on LPS-induced ROS generation and found that ROS accumulation was significantly reduced after pretreatment with WEMF in LPS-stimulated RAW 264.7 macrophages. Therefore, the WEMF-mediated inhibition of ROS generation might be attributed to its ability to scavenge free radicals, and could potentially inhibit the NF- $\kappa \mathrm{B}$ and MAPKs-dependent expression of pro-inflammatory mediators, thereby resulting in an anti-inflammatory efficacy. We further investigated the protective effect of WEMF against LPS-induced NO and ROS generation using DAF-FM-DA and DCF-DA staining in zebrafish as an alternative in vivo animal model system. Consistent with previous results (Wijesinghe et al. 2014, Lee et al. 2015b, Cheong et al. 2016), a dramatic increase in the fluorescence signals was observed in the LPSexposed group unlike in the unstimulated control group, thus indicating that $\mathrm{NO}$ and ROS generation took place during LPS treatment in the zebrafish larvae. However, similar to our in vitro results, a significant reduction in the amount of NO and ROS was observed in zebrafish treated with WEMF prior to LPS treatment, thus indicating the strong antiinflammatory and antioxidant potentials of WEMF.

\section{CONCLUSIONS}

The present results demonstrated that WEMF exerted potent anti-inflammatory and antioxidant effects in RAW 264.7 macrophages and zebrafish.
In LPS-stimulated RAW 264.7 macrophages, WEMF markedly attenuated the production of pro-inflammatory mediators and accumulation of ROS. These effects of WEMF were associated with the suppression of LPS-induced nuclear translocalization of NF- $\kappa \mathrm{B}$ and MAPKs activation. WEMF also significantly prevented the elevation of NO and ROS levels in an LPS-stimulated zebrafish model. Based on the results of this study, WEMF could have a beneficial effect to enhance anti-inflammatory and antioxidant treatment.

\section{ACKNOWLEDGMENTS}

This work was supported by the High Value-added Food Technology Development Program (3140433), Ministry of Agriculture, Food and Rural Affairs, Republic of Korea.

\section{REFERENCES}

ABUAJAH CI, OGBONNA AC AND OSUJI CM. 2015. Functional components and medicinal properties of food: a review. J Food Sci Technol 52: 2522-2529.

ADEREM A AND ULEVITCH RJ. 2000. Toll-like receptors in the induction of the innate immune response. Nature 406: 782-787.

AMIN AR, ATTUR M AND ABRAMSON SB. 1999. Nitric oxide synthase and cyclooxygenases: distribution, regulation, and intervention in arthritis. Curr Opin Rheumatol 11: 202-209.

ANN JY, EO H AND LIM Y. 2015. Mulberry leaves (Morus alba L.) ameliorate obesity-induced hepatic lipogenesis, fibrosis, and oxidative stress in high-fat diet-fed mice. Genes Nutr 10: 46.

BOCANEGRA A, BASTIDA S, BENEDI J, RODENAS S AND SANCHEZ-MUNIZ FJ. 2009. Characteristics and nutritional and cardiovascular-health properties of seaweeds. J Med Food 12: 236-258.

BRÜNE B, DEHNE N, GROSSMANN N, JUNG M, NAMGALADZE D, SCHMID T, VON KNETHEN A AND WEIGERT A. 2013. Redox control of inflammation in macrophages. Antioxid Redox Signal 19: 595-637.

CHAN EW, LYE PY AND WONG SK. 2016. Phytochemistry, pharmacology, and clinical trials of Morus alba. Chin J Nat Med 14: 17-30.

CHAO WW, KUO YH, LI WC AND LIN BF. 2009. The production of nitric oxide and prostaglandin E2 in peritoneal macrophages is inhibited by Andrographis 
paniculata, Angelica sinensis and Morus alba ethyl acetate fractions. J Ethnopharmacol 122: 68-75.

CHEONG SH, YANG HW, KO EY, AHN G, LEE W, KIM D, JEON YJ AND KIM K. 2016. Anti-inflammatory effects of trans-1,3-diphenyl-2,3-epoxypropane-1-one in zebrafish embryos in vivo model. Fish Shellfish Immunol 50: 16-20.

CONTI B, TABAREAN I, ANDREI C AND BARFAI T. 2004. Cytokines and fever. Front Biosci 9: 1433-1449.

CUNHA TM, VERRI WA JR, SCHIVO IR, NAPIMOGA MH, PARADA CA, POOLE S, TEIXEIRA MM, FERREIRA SH AND CUNHA F. 2008. Crucial role of neutrophils in the development of mechanical inflammatory hypernociception. J Leukoc Biol 83: 824-832.

DEEPA M, SURESHKUMAR T, SATHEESHKUMAR PK AND PRIYA S. 2013. Antioxidant rich Morus alba leaf extract induces apoptosis in human colon and breast cancer cells by the downregulation of nitric oxide produced by inducible nitric oxide synthase. Nutr Cancer 65: 305-310.

EOM SA ET AL. 2015. Protective effects of PEP-1-Catalase on stress-induced cellular toxicity and MPTP-induced Parkinson's disease. BMB Rep 48: 395-400.

FREIRE MO AND VAN DYKE TE. 2013. Natural resolution of inflammation. Periodontol 2000 63: 149-164.

FU P, BIRUKOVA AA, XING J, SAMMANI S, MURLEY JS, GARCIA JG, GRDINA DJ AND BIRUKOV KG. 2009. Amifostine reduces lung vascular permeability via suppression of inflammatory signalling. Eur Respir J 33: 612-624.

HADDAD JJ AND LAND SC. 2002. Redox signalingmediated regulation of lipopolysaccharide-induced proinflammatory cytokine biosynthesis in alveolar epithelial cells. Antioxid Redox Signal 4: 179-193.

HONG CH, HUR SK, OH OJ, KIM SS, NAM KA AND LEE SK. 2002. Evaluation of natural products on inhibition of inducible cyclooxygenase (COX-2) and nitric oxide synthase (iNOS) in cultured mouse macrophage cells. J Ethnopharmacol 83: 153-159.

IQBAL S, YOUNAS U, SIRAJUDDIN, CHAN KW, SARFRAZ RA AND UDDIN K. 2012. Proximate composition and antioxidant potential of leaves from three varieties of Mulberry (Morus sp.): a comparative study. Int J Mol Sci 13: 6651-6664.

JEONG JW ET AL. 2016. Mori folium inhibits interleukin$1 \beta$-induced expression of matrix metalloproteinases and inflammatory mediators by suppressing the activation of NF- $\kappa$ B and p38 MAPK in SW1353 human chondrocytes. Int J Mol Med 37: 452-460.

KAMINSKA B. 2005. MAPK signalling pathways as molecular targets for anti-inflammatory therapy-from molecular mechanisms to therapeutic benefits. Biochim Biophys Acta 1754: 253-262.
KAUPPINEN A, SUURONEN T, OJALA J, KAARNIRANTA K AND SALMINEN A. 2013. Antagonistic crosstalk between $\mathrm{NF}-\kappa \mathrm{B}$ and SIRT1 in the regulation of inflammation and metabolic disorders. Cell Signal 25: 1939-1948.

KHAN MA ET AL. 2013. A comparative study on the antioxidant activity of methanolic extracts from different parts of Morus alba L. (Moraceae). BMC Res Notes 6: 24.

KIM DS, KANG YM, JIN WY, SUNG YY, CHOI G AND KIM HK. 2014. Antioxidant activities and polyphenol content of Morus alba leaf extracts collected from varying regions. Biomed Rep 2: 675-680.

KIM GN AND JANG HD. 2011. Flavonol content in the water extract of the mulberry (Morus alba L.) leaf and their antioxidant capacities. J Food Sci 76: C869-873.

KIM SF, HURI DA AND SNYDER SH. 2005. Inducible nitric oxide synthase binds, S-nitrosylates, and activates cyclooxygenase-2. Science 310: 1966-1970.

KOBAYASHI Y, MIYAZAWA M, KAMEI A, ABE K AND KOJIMA T. 2010. Ameliorative effects of mulberry (Morus alba L.) leaves on hyperlipidemia in rats fed a high-fat diet: induction of fatty acid oxidation, inhibition of lipogenesis, and suppression of oxidative stress. Biosci Biotechnol Biochem 74: 2385-2395.

KWON DH ET AL. 2016. The immunomodulatory activity of Mori folium, the leaf of Morus alba L., in RAW 264.7 macrophages in vitro. J Cancer Prev 21: 144-151.

LEE JS, KIM HG, HAN JM, KIM DW, YI MH, SON SW, KIM YA, LEE JS, CHOI MK AND SON CG. 2014. Ethanol extract of Astragali Radix and Salviae Miltiorrhizae Radix, Myelophil, exerts anti-amnesic effect in a mouse model of scopolamine-induced memory deficits. J Ethnopharmacol 153: 782-792.

LEE H, PYO MJ, BAE SK, HEO Y, KIM CG, KANG C AND KIM E. 2015a. Improved therapeutic profiles of PLA2free bee venom prepared by ultrafiltration method. Toxicol Res 31: 33-40.

LEE SH, YANG HW, DING Y, WANG Y, JEON YJ, MOON SH, JEON BT AND SUNG SH. 2015b. Anti-inflammatory effects of enzymatic hydrolysates of velvet antler in RAW 264.7 cells in vitro and zebrafish model. EXCLI J 14: 1122-1132.

LU YC, JAYAKUMAR T, DUANN YF, CHOU YC, HSIEH CY, YU SY, SHEU JR AND HSIAO G. 2011. Chondroprotective role of sesamol by inhibiting MMPs expression via retaining NF- $\kappa \mathrm{B}$ signaling in activated SW1353 cells. J Agric Food Chem 59: 4969-4978.

MCDANIEL ML, KWON G, HILL JR, MARSHALL CA AND CORBETT JA. 1996. Cytokines and nitric oxide in islet inflammation and diabetes. Proc Soc Exp Biol Med 211: 24-32. 
MILLS EL AND O'NEILL LA. 2016. Reprogramming mitochondrial metabolism in macrophages as an antiinflammatory signal. Eur J Immunol 46: 13-21.

MURALIDHARAN S AND MANDREKAR P. 2013. Cellular stress response and innate immune signaling: integrating pathways in host defense and inflammation. J Leukoc Biol 94: 1167-1184.

NAOWABOOT J, PANNANGPETCH P, KUKONGVIRIYAPAN V, KUKONGVIRIYAPAN U, NAKMAREONG S AND ITHARAT A. 2009. Mulberry leaf extract restores arterial pressure in streptozotocininduced chronic diabetic rats. Nutr Res 29: 602-608.

NIKAIDO H. 2003. Molecular basis of bacterial outer membrane permeability revisited. Microbiol Microbiol Mol Biol Rev 67: 593-656.

OH K, MOON HG, LEE DS AND YOO YB. 2015. Tissue transglutaminase-interleukin-6 axis facilitates peritoneal tumor spreading and metastasis of human ovarian cancer cells. Lab Anim Res 31: 188-197.

RAHMAN I AND MACNEE W. 1998. Role of transcription factors in inflammatory lung diseases. Thorax 53: 601612.

RAMAN ST, GANESHAN AK, CHEN C, JIN C, LI SH, CHEN HJ AND GUI Z. 2016. In vitro and in vivo antioxidant activity of flavonoid extracted from mulberry fruit (Morus alba L.). Pharmacogn Mag 12: 128-133.

RIGOGLOU S AND PAPAVASSILIOU AG. 2013. The NF$\kappa \mathrm{B}$ signalling pathway in osteoarthritis. Int J Biochem Cell Biol 45: 2580-2584.

ROCCA B AND FITZGERALD GA. 2002. Cyclooxygenases and prostaglandins: shaping up the immune response. Int Immunopharmacol 2: 603-630.

SHIBATA Y ET AL. 2007. Mulberry leaf aqueous fractions inhibit TNF-alpha-induced nuclear factor kappaB (NF-kappaB) activation and lectin-like oxidized LDL receptor-1 (LOX-1) expression in vascular endothelial cells. Atherosclerosis 193: 20-27.

SUGIMOTO M ET AL. 2009. Mulberry leaf ameliorates the expression profile of adipocytokines by inhibiting oxidative stress in white adipose tissue in $\mathrm{db} / \mathrm{db}$ mice. Atherosclerosis 204: 388-394.

TAN HY, WANG N, LI S, HONG M, WANG X AND FENG Y. 2016. The reactive oxygen species in macrophage polarization: Reflecting its dual role in progression and treatment of human diseases. Oxid Med Cell Longev 2016 : 2795090.

TIRUPATHI RG, SURESH BK, UJWAL KJ, SUJANA P, RAOA AV AND SREEDHAR AS. 2011. Anti-microbial principles of selected remedial plants from Southern India. Asian Pac J Trop Biomed 1: 298-305.

VARGA A, BUDAI MM, MILESZ S, BACSI A, TOZER J AND BENKO S. 2013. Ragweed pollen extract intensifies lipopolysaccharide-induced priming of NLRP3 inflammasome in human macrophages. Immunology 138: 392-401.

WANG L, XU ML, LIU J, WANG Y, HU JH AND WANG MH. 2015. Sonchus asper extract inhibits LPS-induced oxidative stress and pro-inflammatory cytokine production in RAW264.7 macrophages. Nutr Res Pract 9: 579-585.

WIJESINGHE WA, KIM EA, KANG MC, LEE WW, LEE HS, VAIRAPPAN CS AND JEON YJ. 2014. Assessment of anti-inflammatory effect of 5 $\beta$-hydroxypalisadin B isolated from red seaweed Laurencia snackeyi in zebrafish embryo in vivo model. Environ Toxicol Pharmacol 37: 110-117.

XIANG J, TANG YP, ZHOU ZY, WU P, WANG Z, MORI M AND CAI DF. 2010. Apocynum venetum leaf extract protects rat cortical neurons from injury induced by oxygen and glucose deprivation in vitro. Can J Physiol Pharmacol 88: 907-917.

YANG L, BU L, SUN W, HU L AND ZHANG S. 2014. Functional characterization of mannose-binding lectin in zebrafish: implication for a lectin-dependent complement system in early embryos. Dev Comp Immunol 46: 314 322.

ZHANG L AND WANG CC. 2014. Inflammatory response of macrophages in infection. Hepatobiliary Pancreat Dis Int 13: $138-152$.

\section{SUPPLEMENTARY MATERIAL}

Figure S1 - The leaves of M. alba L. (This photo was taken from http://www.cirrusimage.com/tree_weeping_white_ mulberry.htm). 